\title{
Evolution of an elemental theory of Pavlovian conditioning
}

\author{
Allan R. Wagner \\ Yale University, New Haven, Connecticut
}

\begin{abstract}
Kenneth Spence $(1936,1937)$ formalized a quantitative, elemental approach to association theory that has had a broad and dominating influence on learning theory for many years. A set of challenges to the basic approach has spurred the subsequent evolution of elemental theory in various ways. Four of the challenges and some resulting theoretical accommodations are described in the context of Pavlovian conditioning. The evolution involves departures from important specifics of Spence's theory, but is viewed as demonstrating the utility of the basic, elemental approach that is one of his legacies.
\end{abstract}

In the 1930s, Kenneth Spence published an unprecedented quantitative theory of discrimination learning (Spence, 1936, 1937). An important feature of Spence's theory, relevant to the present discussion, is that it contained an elemental characterization of the stimuli that are associated. This was, in itself, not entirely novel. Thorndike (1913, p. 32) had proposed that "all learning is analytic," and that "the bond formed never leads from absolutely the entire situation," but "from parts of the situation to parts of the response." What Spence formalized, and demonstrated the utility of, were the assumptions, first, that stimuli can be usefully conceptualized as comprising numerous elemental components (things like to the right, large, and dark), each of which acquires its own associations; and, second, that behavior to any stimulus reflects the aggregated associative strength of its elements.

Konorski (1948) and Estes (1950) separately generalized on this notion to popularize the assumption that any stimulating circumstance can be conceived as activating a large collection of theoretical elements, which individually enter into association and summate to determine responding.

I am going to describe the evolution of this kind of theory, as I have been involved with it, in the context of Pavlovian conditioning. I will assume it to be commonly understood what such conditioning involves: that some initially neutral stimuli, called conditioned stimuli, or CSs, are trained to signal some significant stimulus, called an unconditioned stimulus, or US, and that the resulting association between the CS and the US is seen in a distinctive conditioned response, or CR, to the CS. However, I will make this more concrete when pointing to specific experimental examples.

Some sense of how elemental theory is typically applied to Pavlovian conditioning can be grasped from Figure 1A, which Konorski (1948) borrowed from Sherrington to describe the representation of two different conditioned stimuli, A and B. It is meant to show that the two stimuli activate populations of neural elements that are different from each other but are partially overlapping. Konorski used it to rationalize a number of basic Pavlovian conditioning phenomena, including stimulus generalization. Konorski's reasoning went like this: Suppose that $\mathrm{CS}_{\mathrm{A}}$ is paired with a US in a manner effective for Pavlovian conditioning. Then it can be assumed that all of the neural elements activated by $\mathrm{CS}_{\mathrm{A}}$ will develop connections to the elements activated by the US, and that this will be seen in the exhibition of a CR when these neural elements are activated again. Now, if the animal is presented for the first time with $\mathrm{CS}_{\mathrm{B}}$, some $\mathrm{CR}$ may also occur, because $\mathrm{CS}_{\mathrm{B}}$ activates some elements that are the same as those activated by $\mathrm{CS}_{\mathrm{A}}$ that are conditioned to the US representation. This has been a common way to conceive of the generalization of conditioned responding from a training CS to a novel CS. Estes (1950) used the same notion to explain stimulus generalization within stimulus-sampling theory. My own quantitative theorizing - for example, in application of the Rescorla-Wagner equation (Rescorla \& Wagner, 1972) and in the basic manner of representing stimuli in my later models, such as SOP and AESOP (Wagner, 1981; Wagner \& Brandon, 1989) - has been in this elemental fashion.

\section{SOME CHALLENGES TO ELEMENTAL THEORY}

Those who are sophisticated about learning theory know that, whereas such an elementa 1 conception may have been in the mainstream since the theorizing of Spence, it has not existed without criticism. Indeed, there have been periodic challenges to the approach, in which it has been supposed that there are sufficient embarrassments that one should feel required to adopt a very dif-

A. R.Wagner, allan.wagner@yale.edu 


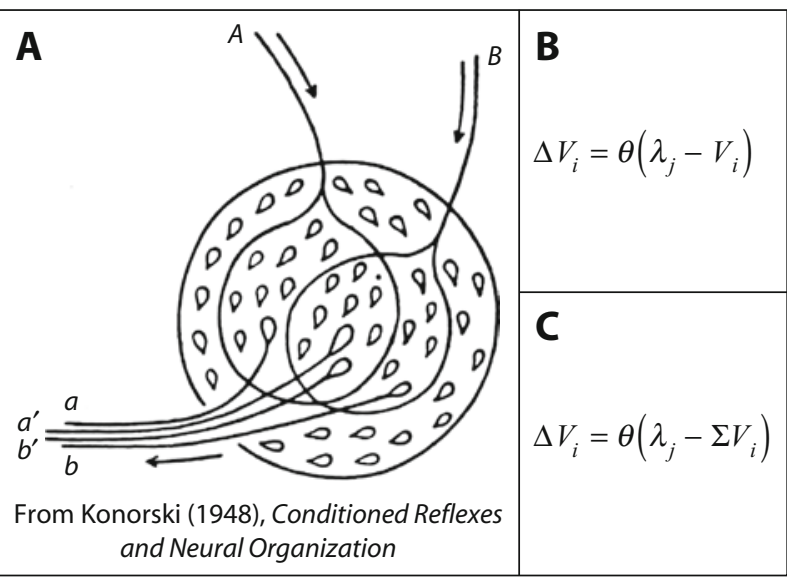

Figure 1. (A) A neural elements characterization that Konorski (1948) borrowed from Sherrington to address phenomena of generalization. $A$ and $B$ are two afferent nerve paths; $a, a^{\prime}, b$, and $b^{\prime}$ are efferent paths. (B) The linear operator rule for learning used by Spence (1956) and Estes (1950). Associative strength, $V_{i}$, is modified according to the difference between the asymptotic level of strength attainable with that reinforcement, $\lambda_{j}$, and the current associative strength of that same cue - that is, $\left(\lambda_{j}-V_{i}\right)$. $\theta$ is a learning rate parameter. $(C)$ The learning rule proposed by Rescorla and Wagner (1972). All terms are the same as in panel B, except that the difference term is computed with $\Sigma V_{i}$, which is the sum of the associative strengths of all the cues present on that learning trial.

ferent theoretical approach. In my presentation, I will take advantage of some of the challenges that have been raised to show how they have led, in a series of steps, to the evolution of a current elemental theory. The four challenges that I will take up involve the facts of (1) errorless discrimination, (2) nonlinear discrimination, (3) context dependence, and (4) situational variation. These have been nontrivial challenges, requiring serious responses.

\section{Errorless Discrimination}

A fundamental problem with the kind of elemental analysis offered by Spence (1936), Konorski (1948), and Estes (1950) is sometimes referred to as the overlap problem and involves the appearance of errorless discrimination. Let's consider again Konorski's characterization in Figure 1A. As reasonable as this elemental treatment is, it was quickly recognized by Bush and Mosteller (1951) that it led to a significant conceptual problem. Suppose that, following training on $\mathrm{CS}_{\mathrm{A}}$ and generalization testing, there is conditioned responding to $\mathrm{CS}_{\mathrm{B}}$ that indicates that $\mathrm{CS}_{\mathrm{A}}$ and $\mathrm{CS}_{\mathrm{B}}$ must have overlapping elements. Suppose, then, that the subject is given discrimination training in which $\mathrm{CS}_{\mathrm{A}}$ continues to be followed by the US but $\mathrm{CS}_{\mathrm{B}}$ is nonreinforced. Prevailing theory made the assumption expressed in Figure 1B, that during such training each elemental association, $V_{i}$, would be strengthened on each reinforced trial according to the distance that $V_{i}$ is from the limit set by the $\lambda$ on reinforced trials (which is greater than 0 ) and would be weakened on each nonreinforced trial according to the distance that $V_{i}$ is from the limit set by the $\lambda$ on nonreinforced trials (which is 0 ). By this rule, the partially reinforced overlapping elements should come to some stable level, at which they would contribute less to conditioned responding to $\mathrm{CS}_{\mathrm{A}}$ than they had initially, but would continue to contribute some, albeit reduced, generalization to $\mathrm{CS}_{\mathrm{B}}$. Discrimination training should never be able to produce errorless discriminative responding to stimuli between which generalization has been exhibited. The fact is, however, that such errorless discrimination performance has frequently been reported (e.g., Robbins, 1970; Uhl, 1964).

There are a number of elemental solutions to this problem. Robert Rescorla and I (Rescorla \& Wagner, 1972) proposed one. We suggested that the answer to the overlap problem (and a variety of other problems) was to be found in a modification of the learning rule. We proposed that the learning to each component of the CS depends not on the associative weight of that component alone, $V_{i}$, but on the total associative weight of all of the components on that trial, $\Sigma V$, as shown in Figure $1 \mathrm{C}$. By this rule, the partial reinforcement of the common elements will still cause them to have some positive $V$. But to the degree that this is so, the $\Sigma V$ on the nonreinforced $\mathrm{CS}_{\mathrm{B}}$ trials will be greater than zero, and the $\Delta V_{i}$ for each of the elements will be negative. As a consequence those elements that are unique to the nonreinforced $\mathrm{CS}_{\mathrm{B}}$, and never reinforced, should be made to have negative associative loadings. Errorless discrimination learning can eventually occur because the negative associative loadings of the elements unique to $\mathrm{CS}_{\mathrm{B}}$ will offset any positive associative loadings of the common cues.

The ability of the Rescorla-Wagner learning rule to account for inhibitory learning in studies with isolable cues is part of what has convinced some that its approach to the overlap problem is a useful one. In any case, it has been the rule used by all of the participants in the story I will tell here.

\section{Nonlinear Discrimination}

There is another apparent problem with an elemental approach to stimulus representation that is commonly emphasized and that was not solved by the Rescorla-Wagner learning rule, without further qualification. The problem is that, according to the simplest elemental characterization of the CS, there are some kinds of (nonlinear) discriminations that should not be solvable but that animals do master.

A study by Maria Saavedra (1975) in our laboratory exemplifies the kind of discrimination problem that is problematic. The study and several others that I will describe employed eyelid conditioning in the rabbit. The use of the rabbit in this form of Pavlovian conditioning is notable in that it was first accomplished by Ken Goodrich, Len Ross, and me when we were working with Kenneth Spence doing human eyelid conditioning (Goodrich, Ross, \& Wagner, 1957, 1959), and was assiduously investigated by Dori Gormezano and his students (e.g., Gormezano, Schneiderman, Deaux, \& Fuentes, 1962), so that it is, arguably, the best characterized example of Pavlovian conditioning today. Due to the neurophysiological work of Dick Thompson (1986) and his students, we also have greater knowledge of the neurocircuitry involved than in any other instance of learning in a vertebrate. The CSs in this case 


\section{Saavedra (1975)}

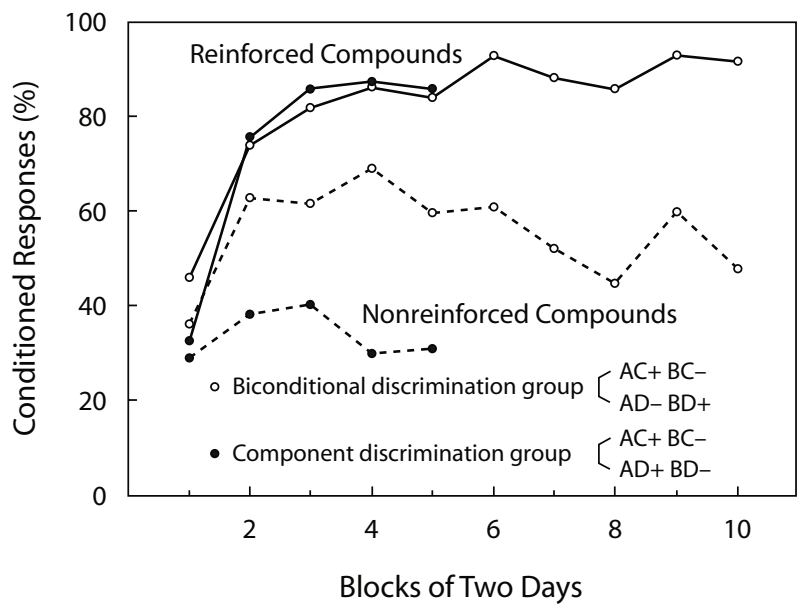

Figure 2. Mean percentages of conditioned responses in 2-day training blocks, corresponding to the biconditional discrimination group and the component discrimination group. Redrawn from Saavedra (1975). The training cues for the two groups are indicated.

variously involve a brief - for example, 1-sec - light, auditory stimulus, or vibratory stimulus applied to the chest, and the US is an eletrotactile stimulus to the cheek that causes an eyeblink response. With pairings of CSs and the US, the CSs also come to elicit a blink response.

Figure 2 specifies the design and the results of the Saavedra (1975) experiment. Saavedra used four compound CSs made up of simultaneous combinations of 1-sec auditory, visual, and vibrotactile stimuli, designated as A, B, C, and D, either reinforced with the paraorbital US (designated + ) or nonreinforced $(-)$. One group received training on a biconditional discrimination of the form indicated by $\mathrm{AC}+, \mathrm{BC}-, \mathrm{AD}-, \mathrm{BD}+$. In this training, all of the constituent stimuli, A, B, C, and D, were equally often reinforced and nonreinforced over the several compounds, so that each should have gained equivalent associative strength. In this case, the compounds that were reinforced, $\mathrm{AC}$ and $\mathrm{BD}$, should have become no stronger with discrimination training than the compounds that were nonreinforced, $\mathrm{AD}$ and $\mathrm{BC}$. But, as may be seen, the rabbits did solve this problem, giving more conditioned eyeblink responses to the reinforced compounds than to the nonreinforced compounds. They did not solve it as easily as other rabbits solved a comparison problem that Saavedra called a component problem, using the same compounds arranged so that those including one of the cues, A, were consistently reinforced and those including an alternative cue, B, were consistently nonreinforced. But, they solved it. The question is, how did they solve it?

Added elements. The solution that was adopted by Wagner and Rescorla (1972) was anticipated by Spence (1952) some years earlier, in his discussion of another nonlinear discrimination problem, so-called negative patterning (Whitlow \& Wagner, 1972). We supposed, like Spence, that there are configural elements that behave just like any other elements, except that they are active not when a single stimulus is present, but when there is a particular conjunction of two or more stimuli. The essence of this reasoning is depicted in the diagram in Figure 3. Any CS, $\mathrm{A}$, is assumed to activate one set of elements, here called memory nodes, and another CS, B, to activate another set of elements, the preponderance of which are assumed to be context independent. The configural assumption is that $\mathrm{CS}_{\mathrm{A}}$ and $\mathrm{CS}_{\mathrm{B}}$, when presented together, and only when presented together, also activate additional, unique elements, representing the conjunction of A and B.

Similar elemental structures would be assumed to obtain for each of the combinations of cues employed in Saavedra's (1975) study. On this reasoning, it should be obvious that subjects should be able to learn to associate any of the compounds with reinforcement versus any others with nonreinforcement, since each carries an element unique to that compound. However, discrimination among some pairs of compounds should be easier than others. Saavedra's component discrimination should have been easier than the biconditional discrimination, because there was a greater proportion of elements in common between like-treated compounds (the two with As and the two with Bs) in this case than in the case of the biconditional discrimination.

\section{Context Dependence}

Theorists who have otherwise challenged elemental theory, such as John Pearce $(1987,1994)$, would surely

\section{Added Elements}

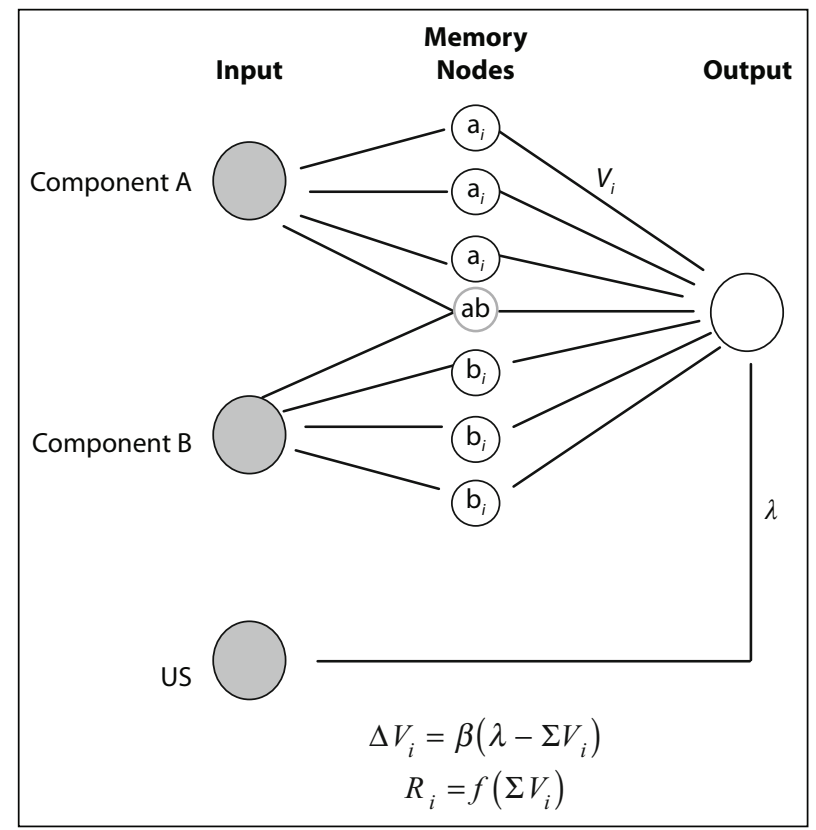

Figure 3. Diagrammatic representation of added-elements theory, as proposed by Wagner and Rescorla (1972), illustrating the presumed elements, here called memory nodes, activated by Stimuli $A$ and $B$ whenever each is presented $\left(a_{i}\right.$ and $b_{i}$, respectively), and the added element (ab) when the two are presented in combination. The two equations express the learning and performance rules of the theory. (See the text for an explanation.) 


\section{Configural Theory}

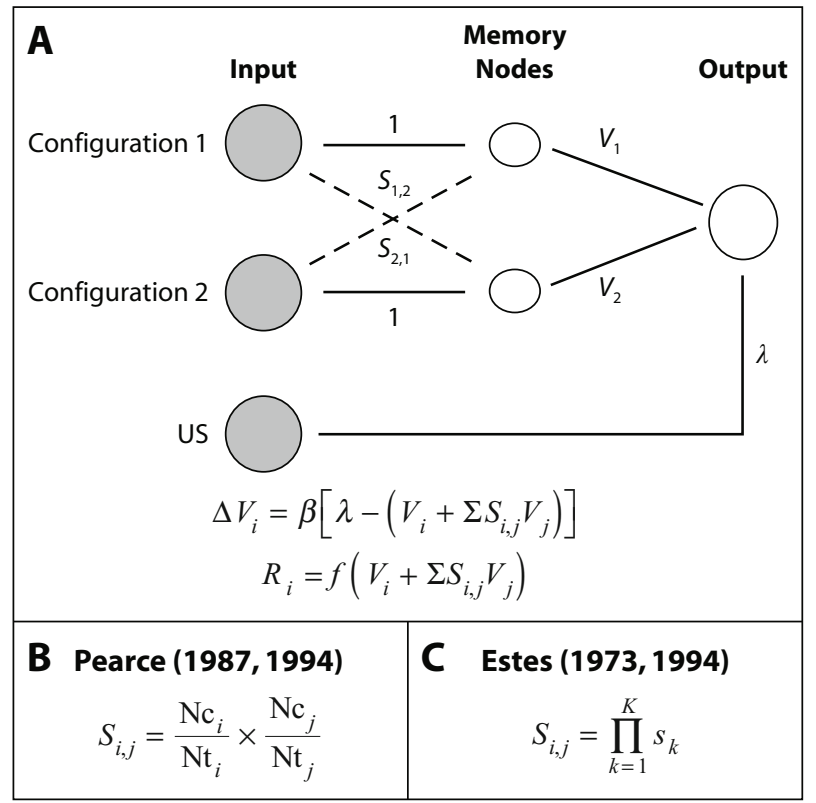

Figure 4. Diagrammatic representation of configural theory, as proposed by J. M. Pearce $(1987,1994)$ and W. K. Estes (1994). (A) Configural representations between which association is presumed to occur and the quantitative rules for learning and performance, analogous to the Rescorla-Wagner rules in Figure 3. The summed tendencies in this case consist of the associative strength directly conditioned to a configuration and that which generalizes from other configurations, assuming similarity, $\mathbf{S}_{i, j}$, between different configurations. (B) Similarity rule proposed by Pearce. (C) Alternative rule proposed by Estes. (See the text for explanations.)

have nominated a different solution to the nonlinear discrimination problem. But they were more vocal in reacting to another set of problems, indicating a degree of context dependence beyond what would be anticipated by the added-elements conception.

One phenomenon is amply revealing of the nature of the problem. It is what Pavlov (1927) called external inhibition. In the simplest case, animals are trained with one CS (call it A) reinforced. Test trials are then administered in which $\mathrm{A}$ is presented, either alone or in compound with another stimulus, B, which is associatively neutral. External inhibition is said to occur when the responding to $\mathrm{A}$ in compound with $\mathrm{B}$ is less than the responding to $\mathrm{A}$ alone. This frequently reported phenomenon (e.g., Reiss \& Wagner, 1972) is not predicted by the Rescorla-Wagner model-with or without added elements. The model assumes that the strength of the CR, like the learning to the component stimuli of a compound, will depend on the sum of the associative strengths, $V_{i}$ of all of the stimuli that are present on a trial-in this case, the sum of the strength of $\mathrm{A}$ alone or of $\mathrm{A}$ and $\mathrm{B}$ together. If $\mathrm{B}$ is associatively neutral, the summed $V$, and, hence, the CR should be the same in the two cases.

Pearce's configural model. On the basis of this and other examples of context dependence, Pearce (1987, 1994) rejected conventional elemental representation in favor of more wholly configural representation. The basic idea relevant to Pavlovian conditioning is indicated in the diagram of Figure 4A. If subjects are trained with any stimulus configuration, they are assumed to form an association between the memory representation of that particular configuration and the US. In the case of the aforementioned external inhibition design, if subjects are trained with an A stimulus, they are presumed to form an association to the representation of that configuration. If they are subsequently tested with an $\mathrm{AB}$ compound, they should respond only because there is some similarity, $S$, between $\mathrm{AB}$ and $\mathrm{A}$ that causes $\mathrm{AB}$ to activate the same memory representation as had been activated by A. Since this tendency should, obviously, be less than unity, there should be less responding to $\mathrm{AB}$ than to $\mathrm{A}$.

The challenge to make this notion work in more than an intuitive fashion adequate for this simple case is in specifying the similarity relationships among different compounds and in specifying how learning and performance to any compound depend on the associative strength conditioned to that configuration, along with that which is occasioned by generalization involving like configurations. Both were well specified by Pearce (1987, 1994). He accepted conditioning and performance rules similar to those of Rescorla and Wagner (1972), but with the relevant summation being across the associative tendency directly conditioned to the configuration that occurred, plus the similarity-weighted associative tendencies of all of the configurations that share some similarity with that configuration. As is described in Figure 4B, the similarity, $S_{i j}$, between any pair of configurations, $i$ and $j$, was taken to be equal to the proportion of the total elements in configuration $i$ that are common to the two configurations, multiplied by the proportion of the elements in configuration $j$ that are common to the two configurations. For example, Stimuli A and AB are, thus, said to have a similarity of .5 to each other, but Stimuli AB and AC are said to have a similarity of only .25 to each other.

Estes's configural model. It is interesting that Estes, surely one of the most influential elemental theorists, came to the same conclusion as Pearce, that the available evidence on context dependence was sufficient to require a configural approach (Estes, 1973, 1994). It is further interesting that he nominated the same learning and performance rules as did Pearce. Where he made a different assumption than Pearce is in the similarity rule that relates different patterns (see Figure 4C). Estes assumes that the functional similarity between any two patterns is well described by the product of their component similarities (where each component similarity is a fraction between 0 and 1). For example, if a subject were exposed to compounds that could be described in terms of the presence or absence of $N$ different dichotomous features, A,B $\ldots N$, the similarity between any two of the compounds would be the product of the similarities of all of their $N$ features.

The different similarity rules employed by Pearce $(1987,1994)$ and Estes $(1973,1994)$ lead to some notable differences in predictions. However, for the present purposes, we can be satisfied with appreciating that both hold that similarity is symmetrical — that is, that the similarity 
of Configuration 1 to Configuration 2 is the same as the similarity of Configuration 2 to Configuration 1 . In the example of external inhibition, it holds that the similarity of $\mathrm{A}$ to $\mathrm{AB}$ is the same as the similarity of $\mathrm{AB}$ to $\mathrm{A}$. On this reasoning, if there is a decrement in responding to $\mathrm{A}$ after training $\mathrm{AB}$, there should be an equal decrement in responding to $\mathrm{AB}$ after training $\mathrm{A}$.

Replaced-elements conception. In response to the challenges concerning context dependence, Susan Brandon and I (Brandon \& Wagner, 1998; Wagner \& Brandon, 2001) proposed an alternative to Wagner and Rescorla's (1972) added elements conception, which we called a replaced-elements conception. We assumed, like Wagner and Rescorla, that representation of any isolable stimulus involves a collection of theoretical elements, some of which are context independent (i.e., will be activated whenever their stimulus is presented) and some of which are context dependent (i.e., will be instantiated or not, depending on the presence or absence of other stimuli). But rather than assuming, as did Wagner and Rescorla, that the only context-dependent elements are ones that are activated when their stimulus is presented in conjunction with some other specific stimulus, we assumed there to be complementary elements that are activated only when their stimulus is presented in isolation from the same specific stimulus. In comparison with the context-dependent elements proposed by Wagner and Rescorla, we assumed there to be not only elements that represent the fact of a stimulus in conjunction with another, but also elements that represent the fact of a stimulus in isolation from another. On this view, representation of a particular compound of stimuli involves the replacement of some elements otherwise contributed by the constituent stimuli in isolation.

This conception is illustrated in Figure 5. In this case, the effective inputs are taken to be component stimuli and the memory nodes representations of different categories of elements. In the two-component world of the diagram, some elements activated by A and B $\left(a_{i}\right.$ and $\left.b_{i}\right)$ are represented as context independent so as to occur whenever A or B are presented. Other of the elements are context dependent and indicated to occur either when the other stimulus is not present $\left(a_{\sim b}\right.$ and $\left.b_{\sim a}\right)$ or when the other stimulus is present $\left(a_{b}\right.$ and $\left.b_{a}\right)$.

Different replacement rules can be formulated, just like the different similarity rules in the configural model, leading to differences in predictions. I will note that the assumption that I now make (Wagner, 2003) is that, if some CS, A, can be presented alone or in either, or both, of two unrelated contexts, $\mathrm{B}$ or $\mathrm{C}$, the replacements resulting from the two contextual manipulations will be statistically independent. Consider there to be some proportion, $r_{\mathrm{b}}$, of the total elements of A that are replaced by A's occurrence in context B, so that the proportion of the elements of $\mathrm{A}$ that are not replaced and will occur both in $\mathrm{A}$ alone and in an $\mathrm{AB}$ compound is $\left(1-r_{\mathrm{b}}\right)$, or $s_{\mathrm{b}}$. Furthermore, consider there to be some proportion, $r_{\mathrm{c}}$, of the total elements of A that are replaced by A's occurrence in context $\mathrm{C}$, so that the proportion of elements of $\mathrm{A}$ that are not replaced and will occur in both $\mathrm{A}$ alone and in an $\mathrm{AC}$ compound is $\left(1-r_{\mathrm{c}}\right)$, or $s_{\mathrm{c}}$. Then, the proportion of the elements of A that are

\section{Replaced Elements}

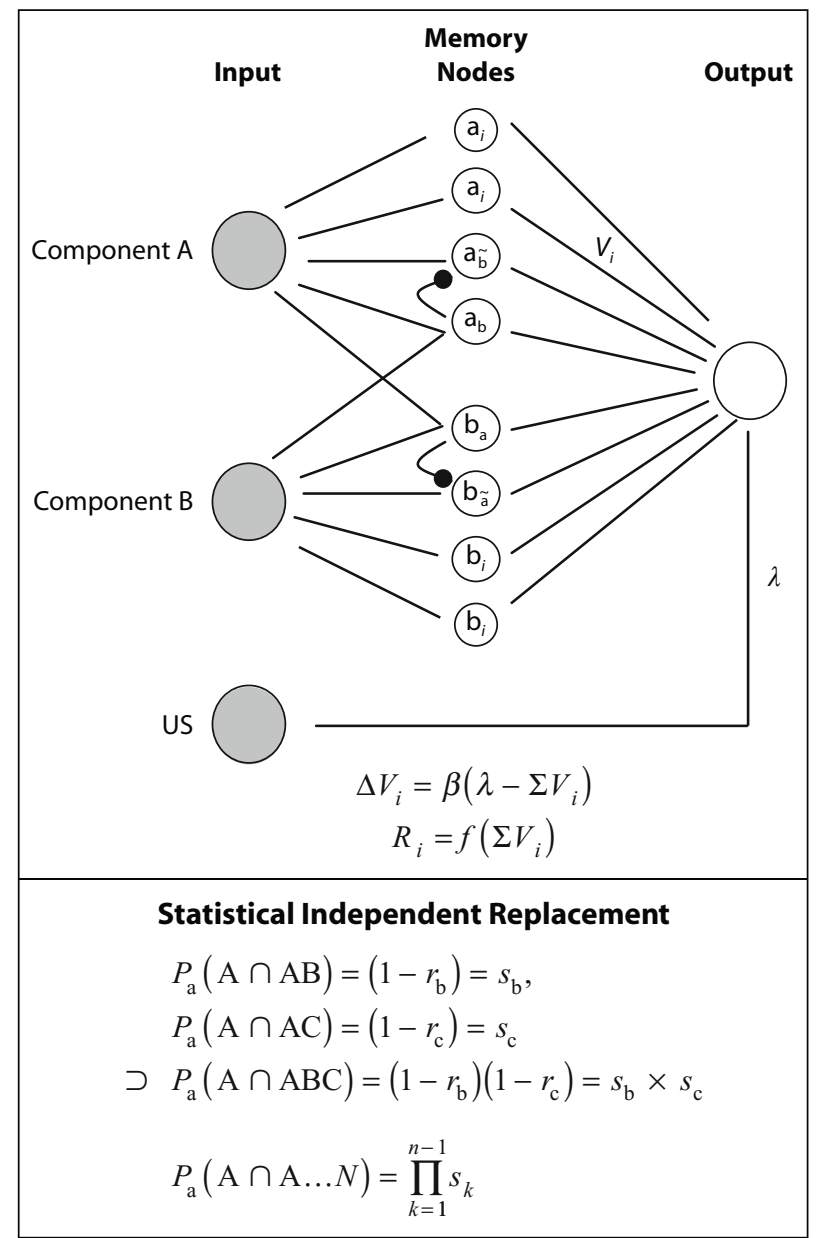

Figure 5. The top panel presents a diagrammatic representation of the replaced-elements model, analogous to the representation in Figure 3. In this case, the presentation of $A$ and $B$ together is taken to activate elements $a_{b}$ and $b_{a}$, in replacement of elements $a_{\sim}$ and $b_{\sim a}$, otherwise occasioned by $A$ and $B$ alone. The lower panel exemplifies the assumed replacement rule: The proportion, $P_{\mathrm{a}}$, of the elements of Stimulus $A$ that are occasioned by both $A$ alone and by $A$ in combination with $B$ and $C$ together is the product of the proportions overlapping between $A$ and $A B$ and between $\mathrm{A}$ and $\mathrm{AC}$. The more general product rule generalizes on this supposition of statistical independence. (See the text for an explanation.)

not replaced by A's occurrence in the context of $\mathrm{B}$ and $\mathrm{C}$ together and that will occur in both $\mathrm{A}$ alone and in an $\mathrm{ABC}$ compound is $\left(1-r_{\mathrm{b}}\right)\left(1-r_{\mathrm{c}}\right)$, or $s_{\mathrm{b}} \times s_{\mathrm{c}}$. This is stated in general form in the equation at the bottom of Figure 5: The proportion of the elements of $A$ that occur in both $A$ and a compound consisting of A and any number of additional orthogonal components is the product of the $s$ values of all of the components other than A. What should be obvious is that this reasoning brings us to the use of a product rule like that proposed by Estes $(1973,1994)$. Our use of it is different. In Estes's configural formulation, the product rule is used to calculate the similarity between any two patterns, depending on their constituent similarities. In 


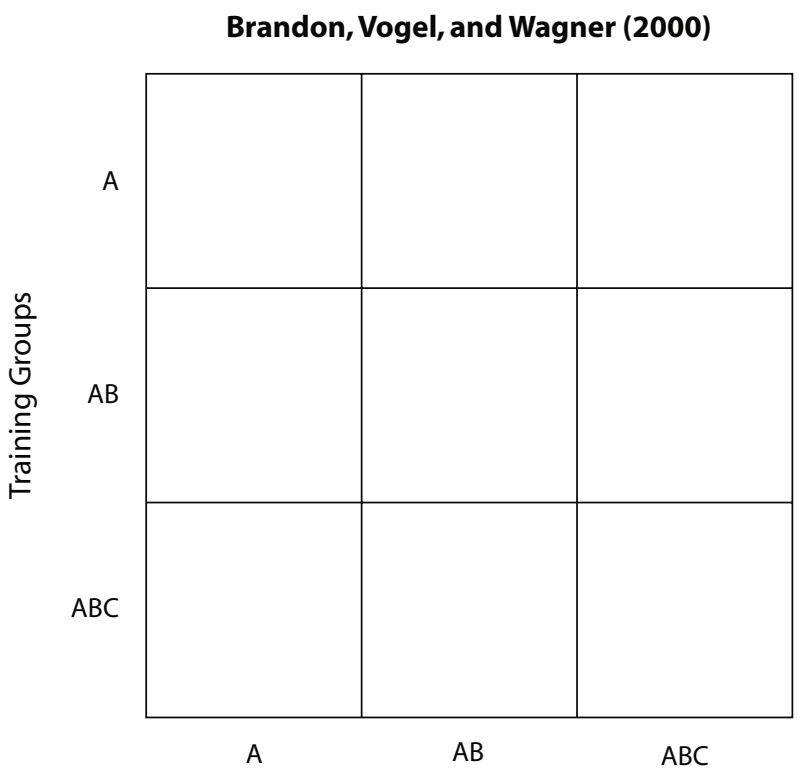

Test Stimuli

Figure 6. Design of the Brandon, Vogel, and Wagner (2000) experiment. Three groups were trained with one of the three indicated CSs and were subsequently tested on all three.

the present elemental formulation, the product rule is used to calculate the similarity in any component's representation, depending on its differing contexts. But the details of such rules are not crucial to the essential conclusions that I will draw here.

Application to a study of generalization. In a study from our laboratory, Brandon, Vogel, and Wagner (2000) assessed a rather fundamental difference in the expectations from the several theories I have mentioned. The study was addressed to the differential predictions that are made when subjects are trained to respond to one CS configuration and then are tested for generalization on a new stimulus configuration that is formed either from removing one or more of the nominal stimuli or from adding one or more new stimuli. The specific design of the study is described in Figure 6. Three groups of rabbits were employed with 1-sec auditory, visual, and vibrotactile stimuli in counterbalanced identification as CSs A, $\mathrm{B}$, and $\mathrm{C}$, and with a paraorbital stimulus as the US. One group was trained with a single stimulus, A, as the CS; another with a compound of two stimuli, AB; and the third with a compound of three stimuli, ABC. After training that was sufficient to bring all three groups to similar stable levels of eyeblink responding to their training stimulus, all three groups were administered equivalent test trials on all three of the stimuli (A, AB, and $A B C)$.

What pattern of test responding should have been expected? Consider once again the Rescorla-Wagner reasoning as depicted in the added-elements stimulus representations in Figure 3. Suppose that a subject were trained on the compound $\mathrm{AB}$ and then tested on $\mathrm{A}$ alone, or were trained with $\mathrm{A}$ alone and then tested on the compound $\mathrm{AB}$. According to the elemental analysis, training on $\mathrm{AB}$ and then testing on A should lead to a considerable generalization decrement: Whatever associative strength had developed to the $\mathrm{b}$ elements and the $\mathrm{ab}$ configural element during training of $\mathrm{AB}$ should be lost in the test of $\mathrm{A}$, which does not include these elements. In contrast, training on $\mathrm{A}$ and then testing on $\mathrm{AB}$ should lead to no decrement: Whatever associative strength had developed to the a elements during training should still be accessible in test, and since the added $\mathrm{b}$ and $\mathrm{ab}$ configural elements should be associatively neutral, they should have no predicted effect. Pearce (1987) had good reason to seize upon this prediction as problematic for the Rescorla-Wagner view: Investigators as early as Pavlov (1927), and including Reiss and Wagner (1972), have reported a decrement as a result of the adding of novel stimuli in test.

Pearce (1987) claimed it as one of the advantages of his configural conception that it avoided the RescorlaWagner prediction. His similarity rule embodies the premise that the generalization decrement from adding a cue (e.g., from testing $\mathrm{AB}$ after training on $\mathrm{A}$ ) is identical to the decrement from removing a cue (e.g., from testing $\mathrm{A}$ after training on $\mathrm{AB}$ ). The Estes configural model employs a different similarity rule, but one that is like Pearce's in being symmetrical: The similarity between $\mathrm{A}$ and $\mathrm{AB}$ is the same as the similarity between $\mathrm{AB}$ and $\mathrm{A}$. If the distinguishing prediction of the Rescorla-Wagner view is that there should be no generalization decrement from adding a stimulus in test, the distinguishing prediction of the Pearce view is that there should be an equal decrement from the adding as from the removing of a cue.

The replaced-element view presents an alternative to both the added-elements and the configural views. Consider the representations of $\mathrm{A}$ and $\mathrm{AB}$ suggested by the replaced-elements conception in Figure 5. If a subject were trained on the $\mathrm{AB}$ compound and then tested on $\mathrm{A}$, there should be considerable generalization decrement due to the loss of the $b$ elements and the ab elements that are in the $\mathrm{AB}$ representation, but not in the A representation. If a subject were trained on the A stimulus and then tested on the $\mathrm{AB}$ compound, there should also be some, albeit a smaller, generalization decrement, due to the loss of the associative strength commanded by the $a \sim b$ elements that are in the A representation but are replaced by the ab elements in the $\mathrm{AB}$ compound. The replacedelement view, unlike the added-element view but like the Pearce and Estes views, predicts that there will be a generalization decrement as a result of either the addition or the withdrawal of a stimulus. On the other hand, like the Rescorla-Wagner view, but unlike the Pearce and Estes views, it predicts that the generalization decrement as a result of adding a stimulus should be less than that as a result of removing a stimulus.

The results of Brandon et al.'s (2000) study are described in Figure 7. The bar graphs display separately for each of the three groups the percentage of eyeblink CRs to the training stimulus and the two generalization test stimuli during the test series. As may be seen, there was less responding to the two novel stimuli than to the training stimulus in each group, whether the novel stimuli involved the removal of stimuli, as it did in the case of the 


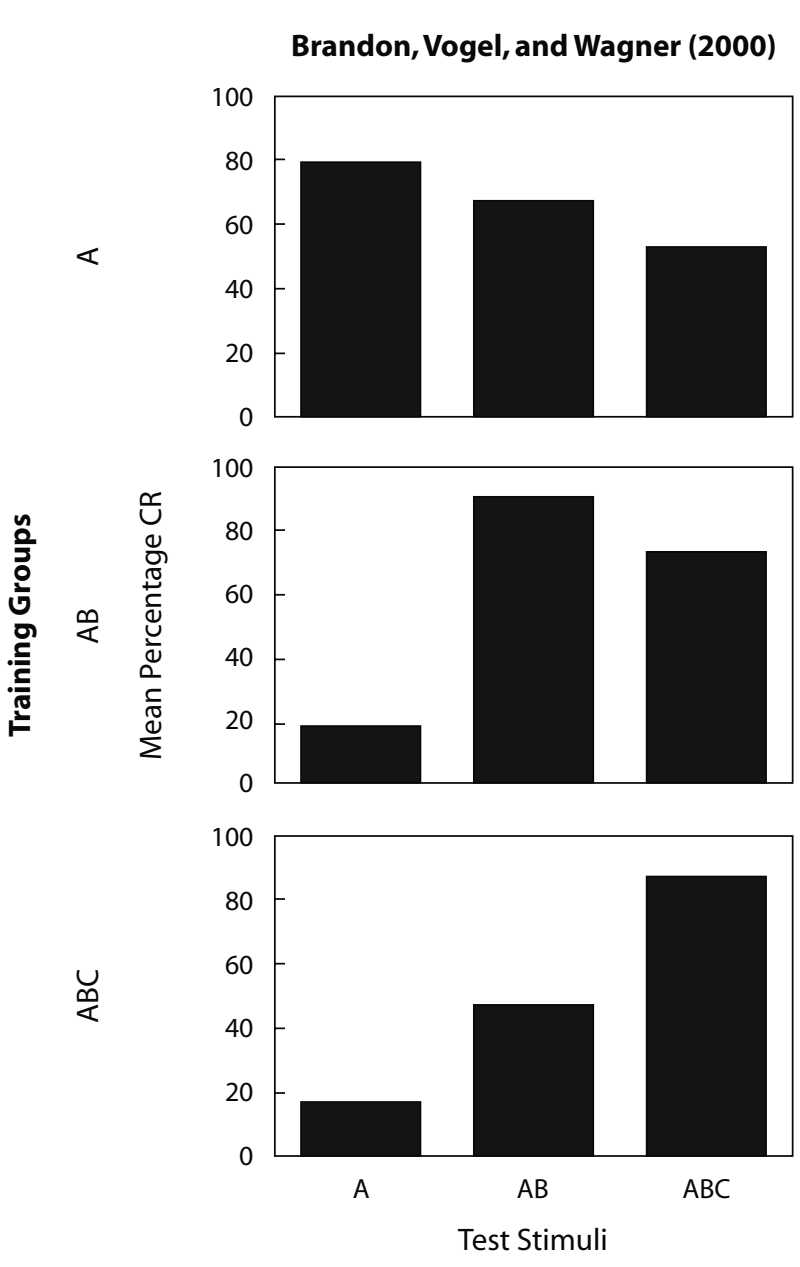

Figure 7. Results of the Brandon, Vogel, and Wagner (2000) experiment described in Figure 6. There was a decrement in responding with both the addition and the withdrawal of stimuli, but more in the latter case.

$\mathrm{ABC}$ group, the addition of stimuli, as it did in the case of the A group, or either the removal or the addition of stimuli, as it did in the case of the AB group. That there was a decrement due to the adding of stimuli is clearly contrary to the Rescorla-Wagner added-element view. As also may be seen, however, the effects of adding or withdrawing a stimulus were not symmetrical, as was predicted by Pearce $(1987,1994)$ and Estes $(1973,1994)$. In all of the direct comparisons, there was a reliably greater decrement produced by the withdrawal of a stimulus than by its addition: There was more of a decrement in conditioned responding when $\mathrm{B}$ was withdrawn from the trained $\mathrm{AB}$ compound than when $\mathrm{B}$ was added to the trained $\mathrm{A}$ cue; there was more of a decrement in conditioned responding when $\mathrm{C}$ was removed from the trained $\mathrm{ABC}$ compound than when $\mathrm{C}$ was added to the trained $\mathrm{AB}$; and there was more of a decrement in conditioned responding when $\mathrm{BC}$ was removed from the trained $\mathrm{ABC}$ compound than when $\mathrm{BC}$ was added to the trained $\mathrm{A}$ cue.

The pattern of the test data observed by Brandon et al. (2000) is in much better accord with the replacedelements view than with either the Rescorla-Wagner added-elements view or the Pearce and Estes configural conceptions. Notably, the essential findings on the asymmetry of the generalization decrement due to the withdrawal versus the adding of a stimulus have since been replicated in several other learning situations (e.g., Glautier, 2004; Gonzalez, Quinn, \& Fanselow, 2003; Wheeler, Amundson, \& Miller, 2006).

\section{Situational Variation}

Prior to the development of the replaced-elements model, there was a considerable number of studies conducted in an attempt to evaluate the relative adequacy of the Rescorla-Wagner added-elements model, versus the Pearce configural model. A troublesome thing about much of this literature is that different outcomes were often reported from the same formal comparison, depending, it appeared, on the experimental situation employed. An advantage of the replaced-element conceptualization over either of the alternatives may be in helping us to see how this situational variation might occur. The following are several examples.

Simple summation. One of the basic expectations of the elemental model of Rescorla and Wagner (1972) is summation. As was previously indicated, in this model, the total associative strength to a compound of stimuli is taken to be equal to the sum of the associative strengths to the several components of that compound. In the simple instance in which two completely dissimilar CSs, A and B, are separately trained and are then presented in compound, the total associative strength to the compound, $\mathrm{AB}$, is assumed to equal the sum of the separate associative strengths to $\mathrm{A}$ and $\mathrm{B}\left[V_{\mathrm{ab}}=\left(V_{\mathrm{a}}+V_{\mathrm{b}}\right)\right]$. Note in this reasoning how it is the explicit assumption that both the associative strength of A and the associative strength of B generalize completely to $\mathrm{AB}$ that yields this strong prediction. In contrast, the configural model of Pearce (1987) predicts no summation in this instance, because Pearce (1987) assumes that each of the associative strengths of the A and B configurations generalizes incompletely to that of AB. Specifically, by Pearce's (1987) generalization rule, $1 / 2\left(V_{\mathrm{a}}\right)$ and $1 / 2\left(V_{\mathrm{b}}\right)$ generalize to $\mathrm{AB}$, so that $V_{\mathrm{ab}}=\left[1 / 2\left(V_{\mathrm{a}}\right)+1 / 2\left(V_{\mathrm{b}}\right)\right]$, or the average of the separate strengths to $\mathrm{A}$ and $\mathrm{B}$. The configural model of Estes goes one step further than the model of Pearce, in predicting that there will be less responding to the $\mathrm{AB}$ compound than to $\mathrm{A}$ and $\mathrm{B}$ alone.

Different studies directed to this issue have produced very different outcomes. Studies that have used stimuli drawn from different modalities have frequently observed summation, in agreement with the elemental model of Rescorla and Wagner (1972). For example, Whitlow and Wagner (1972) reported substantial summation in rabbit eyeblink conditioning when the separate CSs were auditory, visual, or vibrotactile. Their summation data, shown in the left-hand panel of Figure 8, were replicated in another study of eyeblink conditioning by Kehoe, Horne, Horne, and Macrae (1994). Other studies of summation that have employed stimuli from different modalities have most frequently been positive (see Konorski, 1948, using salivary conditioning of dogs; Wagner, 1971, using offbaseline conditioned emotional response conditioning 
Whitlow and Wagner

(1972)

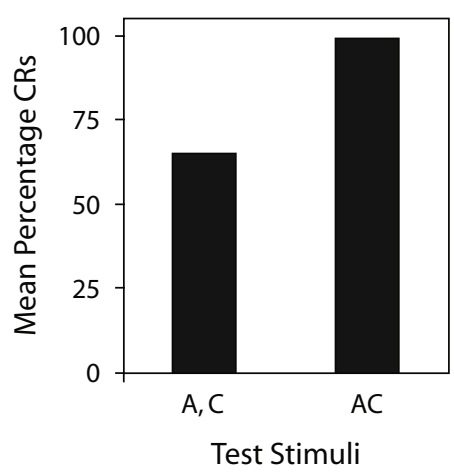

Rescorla and Coldwell

(1995, Exp. 1)

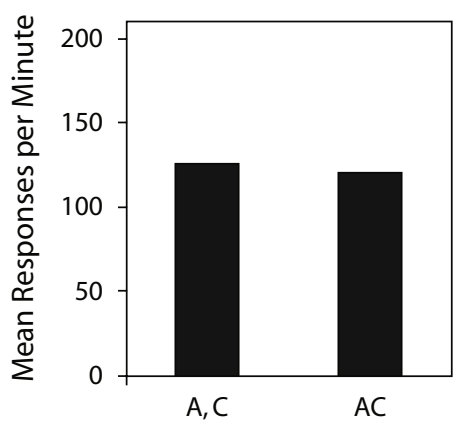

Test Stimuli

Simple Summation Experiments

Figure 8. Results from two experiments on simple summation. Each panel presents the observed responding to two stimuli when presented separately $(\mathrm{A}, \mathrm{C})$ as in training, or in compound (AC), during testing. (See the text for further descriptions of the individual experiments.)

of rats; and Pearce \& Wilson, 1991, and Rescorla, 1997 using magazine approach behavior of rats), although there are some notable exceptions (see Pearce, George, $\&$ Aydin, 2002, using magazine approach). In contrast, summation has generally not been obtained in studies of the autoshaped keypecking behavior of pigeons to combinations of separately trained visual stimuli. For example, Rescorla and Coldwell (1995), in several experiments, trained pigeons to peck to each of two visual patterns that were differently colored and in different locations on a response key, and then tested for response to a compound of the separate stimuli. The data from one of their studies are shown in the right-hand panel of Figure 8. None of the studies produced any greater response to the test compound than to the training components - that is, any summation effect. Aydin and Pearce (1994) reported a similar absence of summation, using compounds of visual stimuli, in agreement with the configural model of Pearce. In fact, Aydin and Pearce $(1995,1997)$ have sometimes reported less responding to a compound than to the constituents, in agreement with the model of Estes.

Figure 9 depicts the predictions from the replacedelements model appropriate to this case of compounding after simple conditioning of two independently trained CSs. As is indicated, it is taken to be the case that Stimuli A and $\mathrm{B}$ have each been trained to the asymptotic value of $\lambda$. The plot depicts, in relationship, the total associative strength predicted on consequent test trials with the $\mathrm{AB}$ compound, depending on the proportion, $r$, of the elements of Stimulus A and of Stimulus B that are assumed to be replaced when the stimuli are presented in compound. In the extreme case in which $r=0$, the model is identical to the Rescorla and Wagner (1972) model, so that the associative strength of the $\mathrm{AB}$ compound is predicted to be equal to the summed associative strengths of A and B. However, the associative strength of the compound is predicted to decrease linearly as the proportion of replaced elements increases. Summation, in the sense of greater associative strength to the com- pound than to either $\mathrm{A}$ or $\mathrm{B}$ alone, is predicted to occur only as $r<.5$. When $r$ is .5, the model predicts an equal associative tendency to the $\mathrm{AB}$ compound as to $\mathrm{A}$ or $\mathrm{B}$ alone; that is, in this instance, it makes the same prediction as the Pearce model. When $r$ is greater than .5, the model predicts less associative tendency to the $\mathrm{AB}$ compound than to A or B alone, consistent with the expectation of the Estes model. Our reasoning should be obvious. In studies using separately trained CSs from different modalities, it can generally be assumed that $r$ is small and in the domain that allows summation. In studies using separately trained visual patterns on a response key, it appears that $r$ is often large

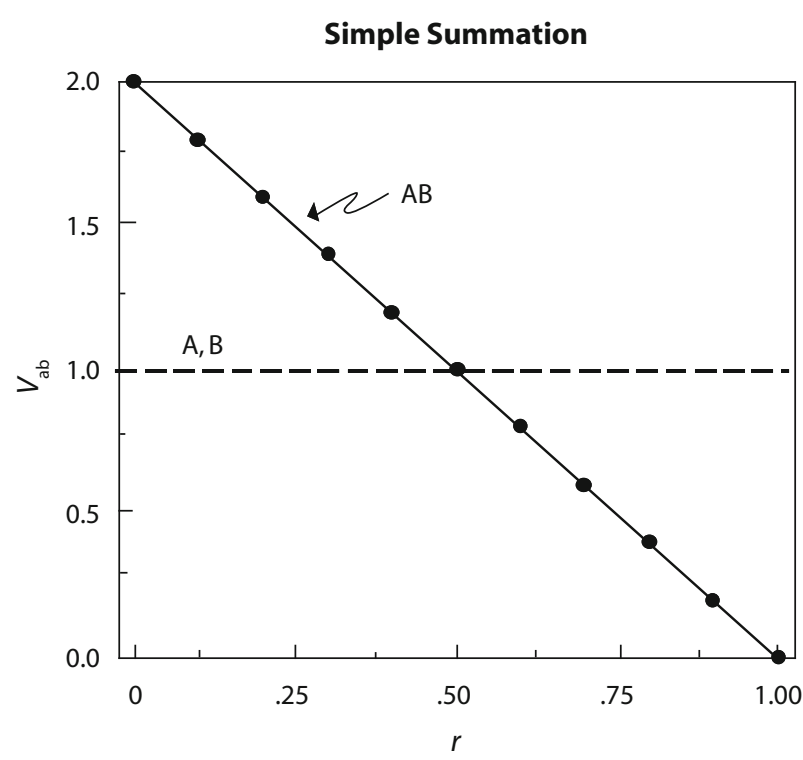

Figure 9. Predicted results in tests of simple summation. It is assumed that $V_{\mathrm{a}}$ and $V_{\mathrm{b}}=\mathbf{1 . 0}$ prior to testing. Depicted is the predicted associative strength $\left(V_{\mathrm{ab}}\right)$ to the test compound, $\mathrm{AB}$, as a function of the proportion, $r$, of the elements of $A$ and $B$ that are assumed to be replaced when the stimuli are compounded. 


\section{Myers, Vogel, Shin, and \\ Wagner (2001, Exp. 2)}

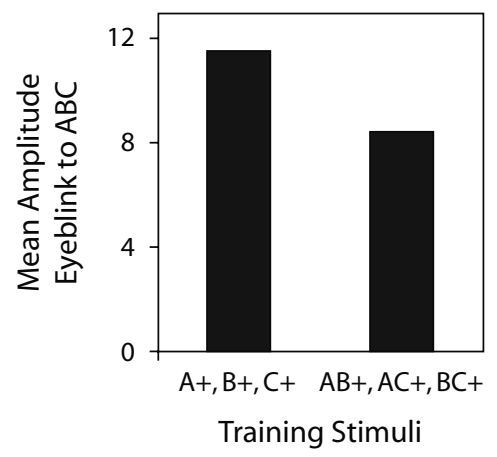

Pearce, Aydin, and

Redhead (1997, Exp. 1)

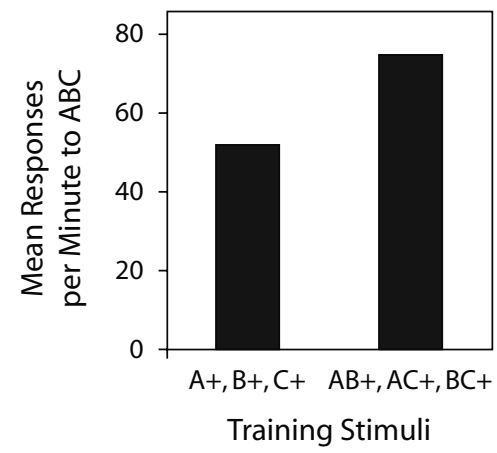

Differential Summation Experiments

Figure 10. Results from two experiments on differential summation. Each panel presents the observed test responding to the compound $\mathrm{ABC}$ after training with the single stimuli $(\mathrm{A}+, \mathrm{B}+, \mathrm{C}+)$ or with the two-stimulus compounds $(\mathrm{AB}+, \mathrm{AC}+, \mathrm{BC}+)$. (See the text for further descriptions of the individual experiments.)

enough to be in the domain that precludes summation and may even be large enough to produce a decrement.

Differential summation. Pearce, Aydin, and Redhead (1997) proposed another experimental comparison for which the Rescorla and Wagner elemental model and the Pearce configural model make different predictions. In this instance, all subjects were trained with the three stimuli (A, B, and C) and then were tested for their response to the three in compound (ABC). One group was trained with each of the three stimuli alone (i.e., with $\mathrm{A}+$, $\mathrm{B}+$, and $\mathrm{C}+$ ), whereas the comparison group was trained with the three possible two-element compounds (i.e., with $\mathrm{AB}+, \mathrm{AC}+$, and $\mathrm{BC}+$ ). The Rescorla-Wagner model predicts a greater responding of the element-trained group (where $V_{\mathrm{a}}, V_{\mathrm{b}}$, and $V_{\mathrm{c}}$ should each go to $\lambda$ and $V_{\mathrm{abc}}$ should equal $3 \lambda$ ) than of the compound-trained group (where $V_{\mathrm{a}}$, $V_{\mathrm{b}}$, and $V_{\mathrm{c}}$ should each go to $0.5 \lambda$ and $V_{\mathrm{abc}}$ should equal $1.5 \lambda)$. In contrast, the Pearce model predicts a greater responding of the compound-trained group than of the element group. The computations are somewhat more complex than those from the Rescorla-Wagner model, but the basic fact is that although there should be less associative strength directly conditioned to the training configurations in the compound group than in the element group $\left(V_{\mathrm{ab}}=V_{\mathrm{ac}}=V_{\mathrm{bc}}=.67\right.$ vs. $\left.V_{\mathrm{a}}=V_{\mathrm{b}}=V_{\mathrm{c}}=1.0\right)$, this difference is more than offset by the greater similarity of the training configurations to the $\mathrm{ABC}$ test stimulus in the compound group than in the element group $(S=.67 \mathrm{vs}$. $S=.33$ ). The configural model of Estes agrees with the directional predictions of the Pearce model in this case, although again predicting less responding to $\mathrm{ABC}$ than to the training stimuli in both groups.

The right-hand panel of Figure 10 summarizes the findings from a study of this design conducted by Pearce et al. (1997). The study employed the autoshaped keypecking of pigeons and used three rectangles that were differently colored and differently positioned on the response key as the three component stimuli. As may be seen, the group that was trained on the $\mathrm{AB}+, \mathrm{AC}+$, and $\mathrm{BC}+$ compounds responded more in testing to the $\mathrm{ABC}$ stimulus than did the group that was trained on the $\mathrm{A}+, \mathrm{B}+$, and $\mathrm{C}+$ single stimuli. These data are in agreement with the predictions of the Pearce model.

Myers, Vogel, Shin, and Wagner (2001, Experiment 2) replicated the design of the Pearce et al. (1997) study but employing rabbit eyeblink conditioning and using a light, tone, and vibrotactile stimulus as the three component stimuli. The data from this experiment are reproduced in the left-hand panel of Figure 10. As may be seen, the data were the opposite of those reported by Pearce et al. (1997). The group that was trained on the $\mathrm{A}+, \mathrm{B}+$, and $\mathrm{C}+$ single stimuli responded more in testing to the $\mathrm{ABC}$ stimulus than did the group that was trained on the $\mathrm{AB}+, \mathrm{AC}+$, and $\mathrm{BC}+$ compounds. These findings are in agreement with the predictions of Rescorla and Wagner (1972).

Figure 11 depicts the predictions from the replacedelements model appropriate to this case of testing an $\mathrm{ABC}$ compound after training with either $\mathrm{A}+, \mathrm{B}+, \mathrm{C}+$ or $\mathrm{AB}+, \mathrm{AC}+, \mathrm{BC}+$. The computation assumed that the single stimuli, or the compound stimuli, in training had each been trained to the asymptotic value of $\lambda$. The plot depicts separately for each of the training conditions the total associative strength predicted on consequent test trials with the $\mathrm{ABC}$ compound, depending on the proportion, $r$, of the elements of $\mathrm{A}, \mathrm{B}$, and $\mathrm{C}$ that are assumed to be replaced when the stimuli are presented in compound. In the extreme case in which $r=0$, the model is identical to the Rescorla and Wagner (1972) model, so that the associative strength of the $\mathrm{ABC}$ compound is calculated to be equal to the summed associative strengths attained by $\mathrm{A}, \mathrm{B}$, and $\mathrm{C}$ in the two conditions - that is, $3 \lambda$ in the element-trained group and $1.5 \lambda$ in the pair-trained group. As the proportion of replaced elements, $r$, increases, the associative strength of the $\mathrm{ABC}$ compound is calculated to decrease regularly for both of the conditions, but following different functions. Thus, the advantage for the element- 


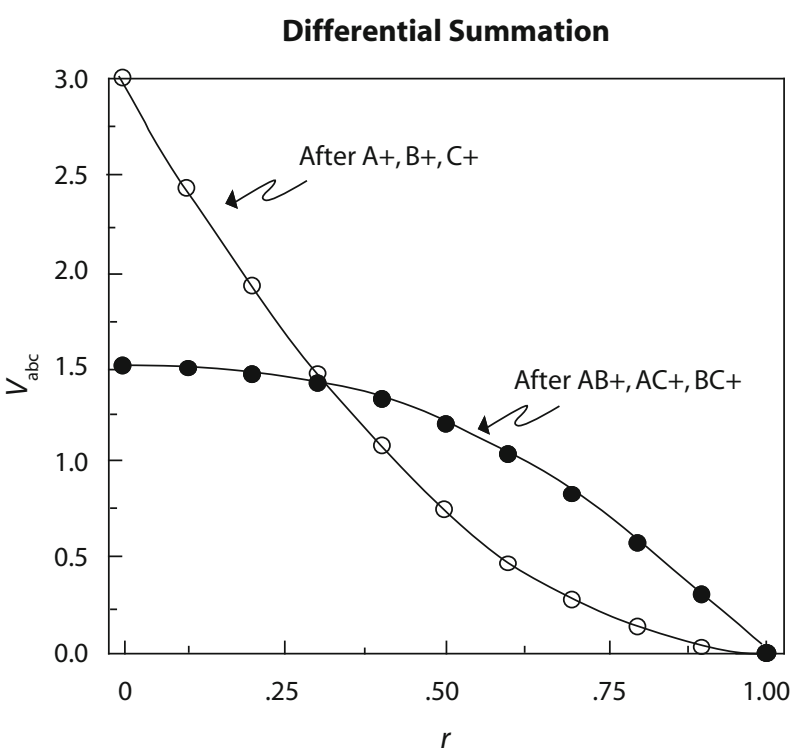

Figure 11. Predicted results in tests of differential summation. It is assumed that as a result of single-stimulus training $(\mathrm{A}+, \mathrm{B}+$, $\mathrm{C}+)$ or paired-stimulus training $(\mathrm{AB}+, \mathrm{AC}+, \mathrm{BC}+) V_{\mathrm{a}}=V_{\mathrm{b}}=$ $V_{\mathrm{c}}=1.0$, or $V_{\mathrm{ab}}=V_{\mathrm{ac}}=V_{\mathrm{bc}}=1.0$. Depicted is the predicted associative strength $\left(V_{\text {abc }}\right)$ to the test compound, $\mathrm{ABC}$, following the two training regimes, as a function of the proportion, $r$, of the elements of $\mathrm{A}, \mathrm{B}$, and $\mathrm{C}$ that are assumed to be replaced when the stimuli are compounded.

trained group exists only as $r$ is less than, approximately, .30. Beyond this point, any difference between the two conditions is in an advantage for the compound-trained group, as otherwise predicted by Pearce (and Estes). Our reasoning should again be obvious. In studies using component CSs from different modalities, as employed by Myers et al. (2001), it can be assumed that $r$ is small and in the domain that produces greater responding of the component-trained group than of the compound-trained group. In studies using component stimuli that consist of different visual patterns on a response key, it is likely that $r$ will be large enough to be in the domain that produces greater responding of the compound-trained group than of the component-trained group.

Reversing a conditioned inhibitor. The last example that I will briefly mention concerns a design that is known to produce a conditioned inhibitor. It is commonly observed that if animals are trained with $\mathrm{A}+, \mathrm{AB}-$, then $\mathrm{B}$ alone will act as a conditioned inhibitor-for example, to reduce the responding to another excitatory CS. According to the simple Rescorla-Wagner model, the discrimination is learned with $\mathrm{AB}$ becoming neutral, as a result of $\mathrm{B}$ 's being driven as negative as A is positive. Pearce's characterization of what happens is again different. Pearce supposes that $\mathrm{AB}$ becomes neutral as the associative strength directly acquired to that configuration becomes as inhibitory as the excitation that generalizes to it from A. On this view, B alone acts inhibitory only as it is similar to AB. Differential predictions follow from the two conceptions, if $\mathrm{B}$ is reinforced alone. According to the RescorlaWagner view, B should ultimately be made positive, rather than negative, and if subjects are tested on $\mathrm{A}$ and $\mathrm{AB}$, they should respond more to $\mathrm{AB}$ than to $\mathrm{A}$ - that is, should show summation. According to Pearce, even if $\mathrm{B}$ is made positive, the generalization of this to $\mathrm{AB}$, following the similarity rule, is incomplete $(1 / 2)$, so that although the responding to $\mathrm{AB}$ will be greater than after original training, it will still be less than that to A. [More specifically, in original training, $\mathrm{A}$ goes to $\{1.33+.5(-.67)\}$ and $\mathrm{AB}$ goes to $\{-.67+.5(1.33)\}$; in the next phase, $\mathrm{B}$ goes to $\{1.33+.5(-.67)\}$; in test, $\mathrm{A}$ is as in Phase 1 (i.e., 1.0) and $\mathrm{AB}$ is $\{-.67+.5(1.33)+.5(1.33)\}$ (i.e., .67).]

The data in Figure 12 present the results from the test phase of experiments with the aforementioned designs. On the right are the results from a study by Pearce and Wilson (1991), using the keypecking response of pigeons to visual stimuli projected on a response key. They show a persistent decrement in responding to $\mathrm{AB}$ relative to $\mathrm{A}$, as was predicted by Pearce. On the left are the results from a study by Shannon Kundey in my laboratory (reported by Kundey \& Wagner, 2003), using the eyeblink conditioned response of rabbits to stimuli in different modalities. They show reliably greater responding to $\mathrm{AB}$ than to $\mathrm{A}$, as is predicted by the Rescorla and Wagner model.

Figure 13 describes how these and related results would be anticipated by the replaced-elements model, assuming prior training of $\mathrm{A}+$ and $\mathrm{AB}-$ that would result in $V_{\mathrm{A}}=1$ and subsequent training with $\mathrm{B}+$ until $V_{\mathrm{B}}=1$. As may be seen, greater responding to $\mathrm{AB}$ than to $\mathrm{A}$, as observed by Kundey and Wagner (2003), is anticipated only when $r$ is relatively small, less than .25 . With any level of replacement greater than .25 , the model predicts that there will be less responding to $\mathrm{AB}$ than to $\mathrm{A}$, as was observed by Pearce and Wilson (1991).

One might be suspicious about the flexibility of a model that appears to be able to fit any outcome with parametric variation (see Pearce, 2002). However, that is not how one should view the way in which the replaced-elements model has related to the conflicting data that I have described. The eyeblink conditioning data from our laboratory that were presented in the three preceding examples, as well as the generalization study of Brandon et al. (2000), all used the same stimuli from different modalities. One would thus expect the outcomes of each study to be predicted by the model, not just with some $r$ value, but using the same or similar $r$ values. That is what occurred. The results of all three studies I have just summarized were predictable on the assumption that $r$ was of the order of .2. And I use that figure because data fitting in the Brandon et al. generalization study was well approached by such an assumption (see Wagner, 2003).

There was more variability in the exact stimuli employed in the three contrasting studies I have mentioned in which autoshaped keypecking to visual compounds was used. But the data from all of them could again be accounted for on the supposition that, in this situation, the proportion of replacement was appreciably greater than that in the eyeblink situation. An obvious way to think about the different outcomes, in those studies using combinations of stimuli from different modalities versus studies using combinations of visual patterns, is in terms of 
Kundey and Wagner

(2003, Exp. 2)

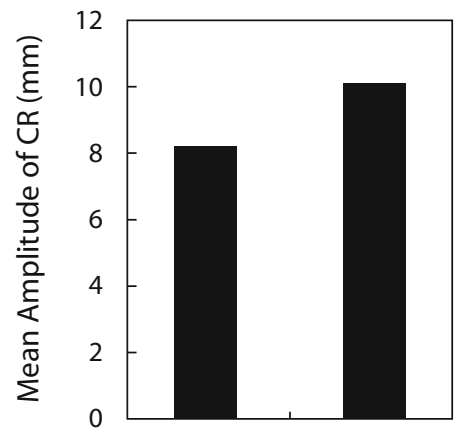

Pearce and Wilson

(1991, Exp. 3)

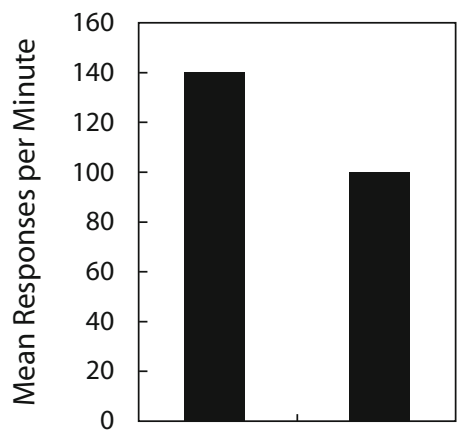

Figure 12. Results from two experiments on reversing a conditioned inhibitor. Each panel presents the observed test responding to Stimulus $A$ and to the compound $\mathrm{AB}$ after conditioned inhibition training with $\mathrm{A}+$ and $\mathrm{AB}-$ and subsequent $B+$ training. (See the text for further descriptions of the individual experiments.)

the degree of perceptual interaction produced. Myers et al. (2001) likened the difference to that which obtains between what Garner (1974) termed separable and integral compounds in multidimensional scaling. In such a scaling circumstance, Roger Shepard (1991) has made the point that the distinction between separable and integral is better treated as involving locations on a continuum, rather than categorical differences. This is, of course, congruent with the notion of different degrees of replacement with different stimulus compounds.

The quandary for us is why results consistent with a relatively high $r$, and with Pearce's configural model, sometimes occur in studies that have used stimuli from different modalities, similar to those in our eyelid conditioning studies. Pearce and Wilson (1991), for example, reported a preserved conditioned inhibition effect in a companion study to the one of theirs that has been mentioned, using lights and tones in a magazine approach study with rats. One possibility is that with unrestrained animals in the typical behavior-conditioning apparatus, the receptororienting behaviors produced by a stimulus in one modality can have an impact on the effective stimulus received in another modality, enough to make $r$ nonnegligible. That is a possibility for tomorrow's research.

\section{CONCLUDING COMMENTS}

Elemental theory has evolved in a number of fruitful ways since the theory offered by Spence in the 1930s. Perhaps the most significant way is in the change in the learning rule. The rule proposed by Rescorla and Wagner (1972) addressed a number of challenges to the linear operator rule that it revised, including the phenomenon of errorless discrimination. It proved to account for the results in a substantial literature on how learning to a CS appears to depend on the relative validity of that cue in relationship to that of others with which it is compounded
(Kamin, 1969; Wagner, 1969; Wagner, Logan, Haberlandt, $\&$ Price, 1968). And it proved to provide a unique account of the occasions on which nonreinforcement acts to produce inhibitory learning (Wagner \& Rescorla, 1972).

Spence (1952) himself embraced the notion of configural elements within elemental theory to deal with the challenging facts of nonlinear discrimination, as exemplified by negative patterning. The further demonstrations of negative patterning by Whitlow and Wagner (1972), and Rescorla (1972), along with the demonstration by

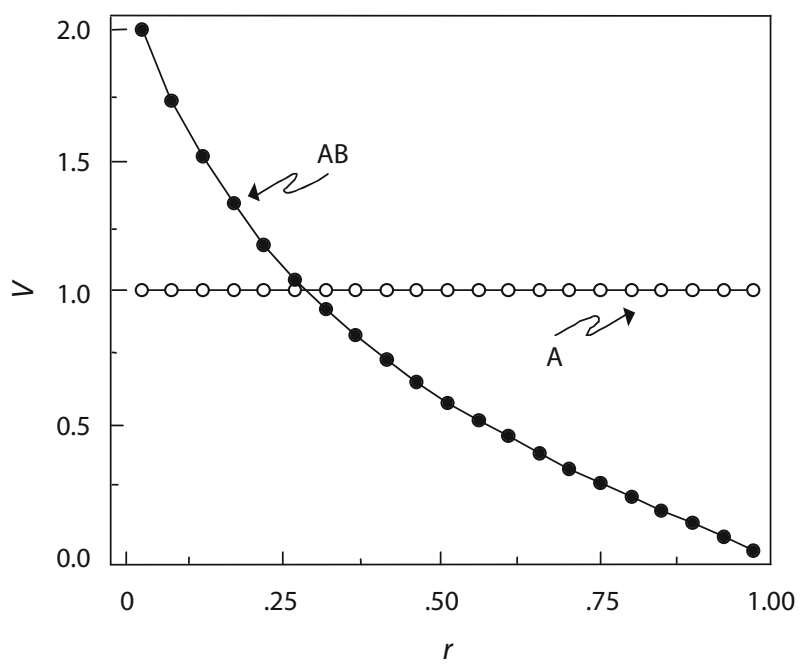

Reversing a Conditioned Inhibitor

Figure 13. Predicted results in tests of the reversing of a conditioned inhibitor. It is assumed that the training with $\mathrm{A}+$ and $\mathrm{AB}-$ results in $V_{\mathrm{a}}=1$ and $V_{\mathrm{ab}}=0$ and that the subsequent training with $\mathrm{B}+$ results in $V_{\mathrm{b}}=1$. Depicted is the predicted associative strength to $A$ and $A B$ in testing, as a function of the proportion, $r$, of the elements of $A$ and $B$ that are assumed to be replaced when the stimuli are compounded. 
Saavedra (1975) of the learning of a biconditional discrimination, provided further impetus for this notion. Wagner (1971) and Wagner and Rescorla (1972) adopted it in what has come to be called an added-elements conception of stimulus compounding. It is interesting that although Spence (1952) acknowledged the necessity of assuming the existence of configural elements in order to account for the learning of some discriminations, he proposed that they could be theoretically ignored in most derivations. Wagner and Rescorla took much the same tack in proposing their added-elements conception, by assuming that configural elements are generally less salient than context-independent elements. This seems a more questionable generalization today.

The most recent challenges to elemental theory involve phenomena of context dependence. It is now recognized that such familiar examples as Pavlov's (1927) observation of external inhibition are pervasive and that contextdependent processes play a substantial role in associative learning. Indeed, Pearce $(1987,1994)$ and Estes (1994) have been so impressed with the phenomena demonstrating context dependence that they have adopted theories in which configurations of cues in context, rather than elements, have become the basic units of association.

These defections notwithstanding, elemental theory, as it has evolved, appears to be quite capable of addressing the facts of context dependence. I have tried to demonstrate this by way of the replaced-elements model (Wagner, 2003). Whether or not the replaced-elements view that I have described will enjoy some life or will quickly be replaced by some other way of dealing with context dependence remains to be seen. It is interesting that it has long seemed intuitive that presenting two stimuli together may occasion stimulus elements that are not provoked by the stimuli alone-for example, such things as the relationship between the stimuli. But it has been less intuitive that the same combinations may occasion the loss of stimulus elements that were provoked by the stimuli alone - for example, such things as their borders of isolation. The replaced-elements notion invites us to consider such a functional possibility. At the least, it invites us to be skeptical that the facts of context dependence necessarily require a basically configural approach.

A challenge for all of the existing theories is to account for the different outcomes that have been reported from the same formal experimental comparisons, such as those evaluating summation. It is to the credit of the replacedelements conception that some differences would be anticipated, depending on variation in the proportion of context-dependent elements - that is, the parameter $r$ assumed to be involved. Whether this is the most adequate way to understand the situational variability remains to be determined. Wagner and Vogel (2007), for example, have pointed out how the same pattern of outcomes concerning summation and reversal of conditioned inhibition as that described here could also be understood in terms of a greater or lesser salience of the contextual cues assumed to be included in the configurations - a notion that Pearce (2002) has proposed in regard to summation.
It has been emphasized that the replaced-element model is like the 1930s theory of Spence in treating the conditioned stimuli as being composed of elemental components with separable associative strengths that summate to determine performance. The more important likeness of this model to that of Spence is, in fact, shared by all of the theories that have been discussed. That likeness is in their computational ability. We could discriminate between the added-elements model, the Pearce-Estes configural models and the replaced-elements model, because all of these theories could make potentially verifiable predictionsfor example, about the relative generalization decrements that would occur with the adding versus the removing of a stimulus. All of the contestant theories are equally indebted to Spence's original theory in this way.

\section{AUTHOR NOTE}

This article is based on a presentation to the conference "Learning and Behavior: A Tribute to Kenneth W. Spence," held at the University of Iowa, September 21-22, 2007. The conference celebrated Spence's life and work in recognition of the 100th anniversary of his birth. Address correspondence to A. R. Wagner, Yale University, P.O. Box 208205, New Haven, CT 06520 (e-mail: allan.wagner@yale.edu).

\section{REFERENCES}

Aydin, A., \& Pearce, J. M. (1994). Prototype effects in categorization by pigeons. Journal of Experimental Psychology: Animal Behavior Processes, 20, 264-277.

Aydin, A., \& Pearce, J. M. (1995). Summation in autoshaping with short- and long-duration stimuli. Quarterly Journal of Experimental Psychology, 42B, 215-234.

Aydin, A., \& Pearce, J. M. (1997). Some determinants of response summation. Animal Learning \& Behavior, 25, 108-121.

Brandon, S. E., Vogel, E. H., \& Wagner, A. R. (2000). A componential view of configural cues in generalization and discrimination in Pavlovian conditioning. Behavioral Brain Research, 110, 67-72.

Brandon, S. E., \& WAGNER, A. R. (1998). Occasion setting: Influence of conditioned emotional responses and configural cues. In N. Schmajuk \& P. C. Holland (Eds.), Occasion setting: Associative learning and cognition in animals (pp. 343-382). Washington, DC: American Psychological Association.

Bush, R. R., \& Mosteller, F. (1951). A model for stimulus generalization and discrimination. Psychological Review, 58, 413-444.

Estes, W. K. (1950). Toward a statistical theory of learning. Psychological Review, 57, 94-104.

Estes, W. K. (1973). Memory and conditioning. In F. J. McGuigan \& D. B. Lumsden (Eds.), Contemporary approaches to conditioning and learning (pp. 265-286). Washington, DC: Winston.

Estes, W. K. (1994). Classification and cognition. Oxford: Oxford University Press.

GARNER, W. R. (1974). The processing of information and structure. Potomac, MD: Erlbaum.

Glautier, S. (2004). Asymmetry of generalization decrement in causal learning. Quarterly Journal of Experimental Psychology, 57B, 315-329.

Gonzalez, F., Quinn, J. J., \& Fanselow, M. S. (2003). Differential effects of adding and removing components of a context on the generalization of conditional freezing. Journal of Experimental Psychology: Animal Behavior Processes, 29, 78-83.

Goodrich, K. P., Ross, L. E., \& Wagner, A. R. (1957). Performance in eyelid conditioning following interpolated presentations of the UCS. Journal of Experimental Psychology, 53, 214-217.

Goodrich, K. P., Ross, L. E., \& Wagner, A. R. (1959). Supplemental report: Effect of interpolated UCS trials in eyelid conditioning without a ready signal. Journal of Experimental Psychology, 58, 319-320.

Gormezano, I., Schneiderman, N., Deaux, E., \& Fuentes, I. (1962). Nictitating membrane: Classical conditioning and extinction in the albino rabbit. Science, 138, 33-34. 
KAMIN, L. (1969). Selective association and conditioning. In N. J. Mackintosh \& W. K. Honig (Eds.), Fundamental issues in associative learning (pp. 42-89). Halifax: Dalhousie University Press.

Kehoe, E. J., Horne, A. J., Horne, P. S., \& Macrae, M. (1994). Summation and configuration between and within sensory modalities in classical conditioning of the rabbit. Animal Learning \& Behavior, 22, 19-26.

KonORSKI, J. (1948). Conditioned reflexes and neuron organization. Cambridge: Cambridge University Press.

Kundey, S. M., \& WAGNer, A. R. (2003, March). Further evaluations of elemental versus configural accounts of Pavlovian conditioning. Paper presented at the 10th Annual International Conference on Comparative Cognition, Melbourne Beach, FL.

Mrers, K. M., Vogel, E. H., Shin, J., \& Wagner, A. R. (2001). A comparison of the Rescorla-Wagner and Pearce models in a negative patterning and a summation problem. Animal Learning \& Behavior, 29, 36-45.

Pavlov, I. P. (1927). Conditioned reflexes: An investigation of the physiological activity of the cerebral cortex (G. V. Anrep, Trans.). Oxford: Oxford University Press.

Pearce, J. M. (1987). A model for stimulus generalization in Pavlovian conditioning. Psychological Review, 94, 61-75.

Pearce, J. M. (1994). Similarity and discrimination: A selective review and a connectionist model. Psychological Review, 101, 587-607.

PeArCE, J. M. (2002). Evaluation and development of a connectionist theory of configural learning. Animal Learning \& Behavior, 30, 73-95.

Pearce, J. M., Aydin, A., \& Redhead, E. S. (1997). Configural analysis of summation in autoshaping. Journal of Experimental Psychology: Animal Behavior Processes, 23, 84-94.

Pearce, J. M., George, D. N., \& Aydin, A. (2002). Summation: Further assessment of a configural theory. Quarterly Journal of Experimental Psychology, 55B, 61-73.

Pearce, J. M., \& Wilson, P. N. (1991). Failure of excitatory conditioning to extinguish the influence of a conditioned inhibitor. Journal of Experimental Psychology: Animal Behavior Processes, 17, 519-529.

ReISs, S., \& WAGNER, A. R. (1972). CS habituation produces a "latent inhibition effect" but no active conditioned inhibition. Learning \& Motivation, 3, 237-245.

Rescorla, R. A. (1972). Configural conditioning in discrete-trial bar pressing. Journal of Comparative Physiological Psychology, 79, 307-317.

RESCORLA, R. A. (1997). Summation: Assessment of a configural theory. Animal Learning \& Behavior, 25, 200-209.

Rescorla, R. A., \& Coldwell, S. E. (1995). Summation in autoshaping. Animal Learning \& Behavior, 23, 314-326.

Rescorla, R. A., \& Wagner, A. R. (1972). A theory of Pavlovian conditioning: Variations in the effectiveness of reinforcement and nonreinforcement. In A. H. Black \& W. K. Prokasy (Eds.), Classical conditioning II: Current research and theory (pp. 64-99). New York: Appleton-Century-Crofts.

RobBINs, D. (1970). Stimulus selection in human discrimination learning and transfer. Journal of Experimental Psychology, 84, 282-298.

SAAVEDRA, M. A. (1975). Pavlovian compound conditioning in the rabbit. Learning \& Motivation, 6, 314-326.

SHEPARD, R. N. (1991). Integrality versus separability of stimulus dimensions: From an early convergence of evidence to a proposed theoretical basis. In G. R. Lockhead \& J. R. Pomeranz (Eds.), Perception of structure: Essays in honor of Wendell R. Garner (pp. 53-71). Washington, DC: American Psychological Association.

SPENCE, K. W. (1936). The nature of discrimination learning in animals. Psychological Review, 43, 427-449.

Spence, K. W. (1937). The differential response in animals to stimuli varying within a single dimension. Psychological Review, 44, 430-444.

SPENCE, K. W. (1952). The nature of the response in discrimination learning. Psychological Review, 59, 89-93.

SPENCE, K. W. (1956). Behavior theory and conditioning. New Haven, CT: Yale University Press.

Thompson, R. F. (1986). The neurobiology of learning and memory. Science, 233, 941-947.

Thorndike, E. L. (1913). Educational psychology: Vol. II. The psychology of learning. New York: Columbia University, Teachers College.

UHL, C. N. (1964). Effect of overlapping cues upon discrimination learning. Journal of Experimental Psychology, 67, 91-97.

WAGNER, A. R. (1969). Stimulus validity and stimulus selection in associative learning. In N. J. Mackintosh \& W. K. Honig (Eds.), Fundamental issues in associative learning (pp. 90-122). Halifax: Dalhousie University Press.

WAGNER, A. R. (1971). Elementary associations. In H. H. Kendler \& J. T. Spence (Eds.), Essays in neobehaviorism: A memorial volume to Kenneth W. Spence (pp. 187-213). New York: Appleton-Century-Crofts.

WAGNER, A. R. (1981). SOP: A model of automatic memory processing in animal behavior. In N. E. Spear \& R. R. Miller (Eds.), Information processing in animals: Memory mechanisms (pp. 5-47). Hillsdale, NJ: Erlbaum.

Wagner, A. R. (2003). Context-sensitive elemental theory. Quarterly Journal of Experimental Psychology, 23B, 7-29.

WAGNer, A. R., \& Brandon, S. E. (1989). Evolution of a structured connectionist model of Pavlovian conditioning (AESOP). In S. B. Klein \& R. R. Mowrer (Eds.), Contemporary learning theories: Pavlovian conditioning and the status of traditional learning theory (pp. 149-189). Hillsdale, NJ: Erlbaum.

WAGner, A. R., \& Brandon, S. E. (2001). A componential theory of Pavlovian conditioning. In R. R. Mowrer \& S. B. Klein (Eds.), Handbook of contemporary learning theories (pp. 23-64). Mahwah, NJ: Erlbaum.

Wagner, A. R., Logan, F. A., Haberlandt, K., \& Price, T. (1968). Stimulus selection in animal discrimination learning. Journal of Experimental Psychology, 64, 191-199.

WAGner, A. R., \& Rescorla, R. A. (1972). Inhibition in Pavlovian conditioning: Applications of a theory. In R. A. Boakes \& M. S. Haliday (Eds.), Inhibition and learning (pp. 301-336). New York: Academic Press.

WAGner, A. R., \& Vogel, E. H. (2007). Configural and elemental processing in associative learning: Commentary on Melchers, Shanks and Lachnit. Behavioural Processes, 77, 446-450.

Wheeler, D. S., Amundson, J. C., \& Miller, R. R. (2006). Generalization decrement in human contingency learning. Quarterly Journal of Experimental Psychology, 59, 1212-1223.

Whitlow, J. W., JR., \& Wagner, A. R. (1972). Negative patterning in classical conditioning: Summation of response tendencies to isolable and configural components. Psychonomic Science, 27, 299-301.

(Manuscript received April 1, 2008; revision accepted for publication May 7, 2008.) 